\section{Valentina Baić}

Ministarstvo unutrašnjih poslova Republike Srbije

\section{Tačnost procene laganja i neverbalnih ponašanja koja indikuju laž i obmanjivanje}

U radu je prezentovano istraživanje u kome je učestvovalo 90 subjekata, studenata Kriminalističko policijske akademije u Zemunu. Deset studenta prve godine studija (6 mladića i 4 devojke) učestovalo je u prvoj fazi u kojoj je pripremljen video materijal koji je kasnije korišcen u samom istraživanju. Uzorak ispitanika činilo je 80 studenata treće i četvrte godine (58 muškaraca i 22 žene starosti između 21-25 godina), koji su imali zadatak da nakon gledanja 10 video klipova (od kojih 5 prikazuju osobu koja govori istinu, a 5 osobu koja govori laž) procene učestalost neverbalnih ponašanja osoba sa snimaka, kao i da daju svoje mišljenje o tome da li je osoba govorila istinu ili laž. Rezultati istraživanja pokazali su da je uspešnost studenata Kriminalističko policijske akademije u proceni istinitosti iskaza bila manja od procene na osnovu slučajnog pogađanja. Utvrđeno je da među ispitanicima postoje izražene individualne razlike u prepoznavanju laganja. Pokazano je da ispitanici koji su uspešniji u proceni istinitosti lažnog iskaza procenjuju da su samododirivanje, pokreti šake, greške u govoru i ilustracije učestaliji oblici neverbalnog ponašanja prilikom laganja, a da su pokreti trupa i pokreti nogu manje učestali u ovakvim situacijama. Ispitanici koji su tačniji u proceni istinitog iskaza procenjuju da su pokreti nogu, oklevanje u govoru i pokreti glave učestaliji, a samododirivanje manje učestalo neverbalno ponašanje kod osoba koje govore istinu. Pokazalo se da ispitanici veruju da se oni koji lažu ponašaju nervoznije od osoba koje govore istinu, što odgovara stereotipnim shvatanjima o neverbalnim indikatorima laganja. Rezultati bi mogli da se iskoriste kao osnova za kreiranje programa edukacije u prepoznavanju laganja.

Ključne reči: neverbalno ponašanje, neverbalni indikatori laganja, laganje, obmana, procena istinitosti iskaza 


\section{Uvod}

Mnogobrojna naučna istraživanja donela su preciznija saznanja o otkrivanju laganja, što je bilo od izuzetnog značaja, jer su takva saznanja protivurečila stereotipnim verovanjima o neverbalnim indikatorima laganja. U jednom takvom istraživanju koje je sproveo Charles Bond i tim od 90 naučnika, koji su ispitali oko 5.000 ljudi u 75 zemalja (Global Deception Research Team, 2006.), na pitanje: "Po čemu znate da vas neko laže?" većina ispitanika navodila je da je odvraćanje pogleda prvi signal koji im pada na pamet, što je tipično stereotipno mišljenje. Odvraćanje pogleda nije ni u kakvoj vezi sa laganjem, već ima veze sa postiđenošću, budući da ljudi često odvraćaju pogled kada se osećaju postiđeni (De Paulo, Charlton, Cooper, Lindsay \& Muhlenbruck, 1997). Charles Bond tvrdi da se verovanje da osobe koje lažu izbegavaju kontakt očima, uklapa u stereotipno mišljenje o tome da je laganje loše (Global Deception Research Team, 2006.).

Rezultati dosadašnjih studija u ovom području pokazuju da su ljudi generalno neuspešni u otkrivanju laži, bilo da je reč o laicima ili profesionalcima (Vrij, 2000). Ekman i O’Sullivan (1991) ispitivali su koliko su uspešni u proceni laži agenti CIA, FBI, agenti nacionalne sigurnosti, istražitelji pljački, sudije, psihijatri, poligrafisti, studenti i drugi zaposleni. Rezultati istraživanja pokazali su da nije utvrđena povezanost između stepena sigurnosti u datu procenu i tačnosti otkrivanja laganja, izuzev kod tajnih agenata, koji su pokazali veći procenat tačnosti. Vrij (2000) je takođe utvrdio da policajci u svojim procenama pokazuju veći stepen sigurnosti, iako je njihov procenat tačnosti bio ispod nivoa koji bi se mogao očekivati na osnovu slučajnosti. Vrij i Winkel (1991) istraživali su tačnost procene laganja kod holandskih detektiva i utvrdili da je ona bila manja od procene na osnovu slučajnog pogađanja. Svoju procenu detektivi su temeljili na manjoj javnoj svesti o sebi, neurednoj odeći, manjem broju osmeha, većoj socijalnoj anksioznosti, manjoj kooperativnosti i većem broju pokreta rukama i ramenima tokom ispitivanja.

U jednoj studiji (Vrij, 2000) pokazalo se da opažači, tačnije - laici i osobe zaposlene u pravno-kaznenom sistemu, sa laganjem najčešće povezuju znakove anksioznosti kao što su: greške u govoru, povišen glas, duga latencija odgovora, skretanje pogleda, smeh i učestali pokreti delova tela. Ovi nalazi su bili veoma značajni jer su ukazivali da procenjivači prilikom procene laganja polaze od pretpostavke da će oni koji lažu biti anksiozni (Riggio \& Friedman, 1983), odnosno da se navedena neverbalna ponašanja smatraju znakovima laganja jer se njima krše norme očekivanog ponašanja, što kod opažača pobuđuje sumnju (Vrij, 2000). 
Budući da profesionalci (policajci, sudije, zaposleni u kazneno popravnim ustanovama itd.), kao i laici, imaju pogrešna i stereotipna mišljenja o neverbalnim indikatorima laganja, pretpostavlja se da oni kroz svoje profesionalno iskustvo ne nauče kako da tačno interpretiraju neverbalno ponašanje (Vrij, 2000).

Problematika prepoznavanja laganja na osnovu neverbalnog ponašanja nije dovoljno empirijski istraživana na našim prostorima, dok su u inostranoj, naročito anglosaksonskoj literaturi, prilično zastupljena istraživanja koja se bave ovom tematikom. Iz navedenog razloga pristupilo se istraživanju sa osnovnim ciljem da se utvrdi da li studenti-posmatrači (studenti Kriminalističko policijske akademije) mogu da naprave validne procene učestalosti neverbalnih ponašanja i da li nakon toga mogu uspešno da detektuju laganje. Može se pretpostaviti da su studenti tokom školovanja edukovani u navedenoj oblasti, te da će njihova procena laži i istine biti značajno veća od one koja se očekuje na osnovu slučajnosti. Dosadašnji pregled istraživanja pokazuje da uspešnost profesionalaca (policajci, carinici, sudije itd.) u otkrivanju laži uglavnom ne nadmašuje "laike“, iako su neke grupe profesionalnih procenjivača laži (agenti CIA) bile tačnije u prepoznavanju laži ili su pokazivale veći stepen sigurnosti u tačnost svojih procena. Takođe se pretpostavlja da će se procenjivači u svojoj proceni najčešće oslanjati na ponašanja za koja postoje stereotipna verovanja da su povezana sa obmanjivanjem, kao što su gledanje u oči, povećan broj pokreta, greške u govoru i druge. Istraživanje se bavi pitanjem da li postoji povezanost između uspešnosti u proceni istinitosti iskaza i procene učestalosti pojedinih oblika neverbalnih ponašanja, $\mathrm{s}$ ciljem da se utvrdi eventualna veza između objektivne tačnosti procene i obrasca subjektivnih kriterijuma na kojoj se procena zasniva.

\section{Metod}

\section{Instrument}

Za potrebe ovog istraživanja adaptiran je Vrij-ov upitnik za brzu procenu neverbalnog ponašanja, koji se sastoji od liste oblika neverbalnih ponašanja, kojima je pridružena Likertova 5 -stepena skala procene učestalosti javljanja.

Izbor neverbalnih ponašanja upotrebljenih u zadatku procene zasnovan je na nalazima dve studije (Vrij et al., 2000.).

U zadatak procene bilo je uključeno 10 neverbalnih ponašanja, označenih brojevima od 1 do 10. To su: osmeh, ilustracije, samododirivanje, pokreti šake $i$ prstiju, pokreti nogu i stopala, pokreti glave, pokreti trupa, promena položaja, 
oklevanje u govoru i greške u govoru.

Procene navedenih neverbalnih ponašanja date su na petostepenoj Likertovoj skali, gde je (1) nije se javljalo, (2) javljalo se veoma retko, (3) javljalo se retko, (4) češće se javljalo i (5) javljalo se veoma često.

\section{Uzorak ispitanika}

U istraživanju su učestvovali studenti Kriminalističko policijske akademije u Zemunu. Deset studenta prve godine studija (6 mladića i 4 devojke) učestvovalo je u pripremi video materijala za zadatak procene, dok je sam uzorak ispitanika činilo 80 studenata treće i četvrte godine (58 muškaraca i 22 žene starosti između 21-25 godina).

\section{Postupak}

Istraživanje je sprovedeno u prostorijama Kriminalističko policijske akademije u Zemunu i obuhvatalo je dve faze. U prvoj fazi istraživanja grupa od 10 studenata prve godine Kriminalističko policijske akademije podeljena je slučajnim izborom u dve podgrupe, grupu od 5 studenata koji su davali istinit iskaz i grupu od 5 studenata koji su davali lažni (obmanjujući) iskaz. Ispitanici koji su davali istinit iskaz imali su zadatak da detaljno opišu fotografiju prijatnog sadržaja. Ispitanici koji su davali obmanjujući iskaz gledali su fotografiju neprijatnog sadržaja i njihov zadatak je bio da je detaljno opišu kao da gledaju fotografiju prijatnog sadržaja, dakle da daju lažan opis. Na taj način u obema grupama izjednačen je afektivni ton koji se prenosi porukom. Ispitanicima iz obe grupe sagovornik (istraživač) je postavljao ista pitanja, tražeći razjašnjenja ili izražavajući sumnju u ono što pričaju. Svi ispitanici opisivali su različite fotografije, kako bi se izbeglo kasnije prepoznavanje istinitosti iskaza na osnovu verbalnog sadržaja. Intervjui su snimljeni video kamerom. Na ovaj način pripremljeno je deset video klipova za zadatak procene.

U drugoj fazi istraživanja procenjivači, tačnije studenti III i IV godine Kriminalističko policijske akademije ( 58 muškaraca i 22 žene) u svojstvu procenjivača, gledali su 10 video klipova prikazanih slučajnim redosledom. Nakon svakog prikazanog snimka, studenti-procenjivači popunjavali su Vrijov upitnik za brzu procenu neverbalnog ponašanja, gde su na petostepenoj Likertovoj skali (od „nikad“ do „veoma često“) ocenjivali frekvenciju (učestalost) neverbalnih ponašanja koja se označavaju kao indikatori laganja, i ujedno iskazali svoje mišljenje o tome da li osoba sa snimka laže ili govori istinu. 


\section{Rezultati}

\section{Tačnost procene}

Rezultati istraživanja pokazuju da tačnost procene kod ispitanika u ovom istraživanju nije značajno veća od one koja se mogla očekivati na osnovu slučajnosti (tabela 1.). Procenat tačne detekcije laži i istine iznosio je $48,9 \%$, što je ispod nivoa šanse od 50\%. Rezultati svakog pojedinačnog posmatrača-studenta (prilog 7.), pokazuju da je, od ukupno 80 procenjivača, njih 28 ili 35\% imalo procenat tačnih procena iznad nivoa šanse od $50 \%$. Konačna tačnost kretala se od skromnih $20 \%$ do visokih $80 \%$. Međutim procenat tačnosti od $80 \%$ imala su svega 3 procenjivača ili $3,75 \%$, dok su procenat tačnosti od $70 \%$, imala 4 procenjivača ili 5\% . Najveći procenat iznad nivoa šanse koji je iznosio 60\% imao je 21 procenjivač ili $26,3 \%$, dok je čak 38 ili $47,5 \%$ procenjivača imalo procenat tačnosti ispod nivoa šanse od $50 \%$.

Tabela 1 Procena istinitosti iskaza - tačnost procene

\begin{tabular}{ccc}
\hline & Tačna procena & Netačna procena \\
$\%$ & $\%$ \\
\hline 1 & 48.3 & 51.8 \\
\hline 2 & 49.5 & 50.5 \\
\hline 3 & 48.9 & 51.1 \\
\hline
\end{tabular}

Povezanost tačnosti procene lažnog iskaza i subjektivne procene učestalosti neverbalnih ponašanja

U cilju utvrđivanja povezanosti tačnosti procene lažnog iskaza i subjektivne procene učestalosti neverbalnih ponašanja, primenjena je kategorijalna multipla regresiona analiza. Kriterijska varijabla u analizi bila je prosečna tačnost procene lažnog iskaza. Tačnost procene lažnog iskaza izračunata je kao prosek tačnosti procena za pet "glumaca“ koji su davali lažan iskaz. Skup prediktora činile su prosečne procene učestalosti 8 neverbalnih ponašanja, izračunate za pet "glumaca". Sve varijable definisane su kao varijable na ordinalnom nivou merenja. 
Tabela 2 Parcijalni doprinosi prediktora

\begin{tabular}{lccccc}
\hline & Beta & Std. greška & $\mathrm{df}$ & $\mathrm{F}$ & $\mathrm{p}$ \\
\hline Ilustracije & .255 & .109 & 4 & 5.502 & .001 \\
\hline Samododirivanje & .405 & .114 & 2 & 12.761 & .000 \\
\hline Pokreti šake & .343 & .109 & 5 & 9.860 & .000 \\
\hline Pokreti nogu & -.221 & .108 & 3 & 4.190 & .010 \\
\hline Pokreti glave & -.163 & .110 & 3 & 2.221 & .097 \\
\hline Pokreti trupa & -.581 & .115 & 3 & 25.590 & .000 \\
\hline Oklevanje u govoru & .177 & .103 & 1 & 2.955 & .092 \\
\hline Greške u govoru & .267 & .102 & 3 & 6.820 & .001 \\
\hline
\end{tabular}

$R=0.73 ; R^{2}=0.53 ;$ Korigovani $R^{2}=0.31 ; F(24.50)=2.36 . p=0.005$

Vrednost korigovanog koeficijenta determinacije ukazuje da se približno 31\% varijabiliteta kriterijske varijable može objasniti na osnovu prediktorskog skupa. Najviši parcijalni doprinos, sa negativnim predznakom, ima procena učestalosti pokreta trupa. Procena učestalosti pokreta nogu je takođe negativno povezana sa kriterijskom varijablom, ali je povezanost nižeg intenziteta. Pozitivnu vezu sa tačnošću procene lažnog iskaza ostvaruju procene učestalosti $s a$ mododirivanja, pokreta šake, grešaka u govoru i procena učestalosti ilustracija.

Dakle, sa većom tačnošću procene lažnog iskaza korespondira procena pokreta trupa i pokreta nogu kao manje učestalih i procena samododirivanja, pokreta šake, grešaka u govoru i ilustracija kao učestalijih.

\section{Povezanost tačnosti procene istinitog iskaza i subjektivne procene učestalosti neverbalnih ponašanja}

U cilju utvrđivanja povezanosti tačnosti procene istinitog iskaza i subjektivne procene učestalosti neverbalnih ponašanja, primenjena je kategorijalna multipla regresiona analiza. Kriterijska varijabla u analizi bila je prosečna tačnost procene istinitog iskaza. Tačnost procene istinitog iskaza izračunata je kao prosek tačnosti procena za pet "glumaca“ koji su davali istinit iskaz. Skup prediktora činile su prosečne procene učestalosti 8 neverbalnih ponašanja, izračunate za pet "glumaca“. Sve varijable definisane su kao varijable na ordinalnom nivou merenja. 
Tabela 3 Parcijalni doprinosi prediktora

\begin{tabular}{lccccc}
\hline & Beta & Std. greška & df & $F$ & $\mathrm{p}$ \\
\hline Ilustracije & -.190 & .120 & 3 & 2.533 & .067 \\
\hline Samododirivanje & -.196 & .109 & 2 & 3.247 & .047 \\
\hline Pokreti šake & -.211 & .126 & 1 & 2.809 & .100 \\
\hline Pokreti nogu & .408 & .128 & 3 & 10.132 & .000 \\
\hline Pokreti glave & .259 & .119 & 4 & 4.732 & .002 \\
\hline Pokreti trupa & -.201 & .135 & 2 & 2.225 & .118 \\
\hline Oklevanje u govoru & .375 & .138 & 4 & 7.436 & .000 \\
\hline Greške u govoru & .173 & .139 & 3 & 1.555 & .211 \\
\hline R & & & & & \\
\hline
\end{tabular}

$R=0.65 ; R^{2}=0.42 ;$ Korigovani $R^{2}=0.18 ; F(22.52)=1.73 . p=0.055$

Regresioni model je marginalno statistički značajan. Vrednost korigovanog koeficijenta determinacije sugeriše da skup prediktora objašnjava približno $18 \%$ varijanse kriterijske varijable. Značajne parcijalne doprinose predikciji tačnosti procene istinitog iskaza imaju subjektivne procene pokreta nogu, oklevanja $u$ govoru, i pokreta glave sa pozitivnim predznakom i procena učestalosti samododirivanja sa negativnim predznakom.

Sa procenom tačnosti istinitog iskaza korespondira procena pokreta nogu, oklevanja u govoru i pokreta glave kao učestalijih, i procena samododirivanja kao manje učestalog.

\section{Diskusija}

Rezultati istraživanja pokazali su da je tačnost procene laži od strane studenata Kriminalističko policijske akademije bila manja od procene na osnovu slučajnog pogađanja. Svega tri procenjivača su se pokazala uspešnima, uz tačnost procene koja je iznosila $80 \%$, dok je čak $65 \%$ procenjivača imalo procenat tačnosti $50 \%$ ili ispod $50 \%$. Drugim rečima, rezultati ovog istraživanja pokazuju da su pouzdane procene laži na osnovu posmatranja neverbalnog ponašanja moguće, ali da su one veoma retke.

Analizom rezultata svakog pojedinačnog posmatrača-studenta utvrđeno je da postoje izražene individualne razlike u prepoznavanju laganja među studentima Kriminalističko policijske akademije. Ova razlika se može protumačiti kao razlika u sposobnosti prepoznavanja laganja, iako se ne mora nužno raditi o sposobnosti. Tačnost procene kretala se od skromnih $20 \%$ do visokih $80 \%$. Ovo 
istraživanje je, kao i veliki broj sličnih studija detekcije laži (Vrij, 2000; Kapardis, 2001; Köhnken, 1987; Ekman \& O’Sullivan, 1991 itd.), pokazalo da su od ukupno 80 samo 3 studenta (3,75\%) mogla precizno da uoče laž. Budući da ovim istraživanjem nije bilo predviđeno da studenti-procenjivači usmeno objasne na čemu su temeljili svoje odluke, preostaje nam da pretpostavimo ili da su pomenuta tri studenta prirodno "talentovana" i da imaju izraženu sposobnost percepcije, ili da je njihova tačnost od $80 \%$ bila čista slučajnost.

Postavlja se pitanje da li se dobri i loši procenjivači laganja razlikuju po prepoznavanju javljanja, odnosno nejavljanja specifičnih neverbalnih znakova. Naime, kada je u pitanju ocena istinitosti iskaza, bilo je relativno lako objektivno utvrditi da li je procena tačna ili netačna, dok se kod prepoznavanja neverbalnih znakova teško može reći koja je procena tačna, a koja pogrešna, budući da su procenjivači svoje procene davali na skalama koje nisu uporedive sa objektivno utvrđenim frekvencijama. Stoga se ovde radi o subjektivnoj proceni učestalosti neverbalnih ponašanja, pri čemu se tačnost te procene ne razmatra. Naime, subjektivna procena ispitanika o učestalosti neverbalnih ponašanja se može posmatrati kao osnov njihovih naivnih teorija o neverbalnim indikatorima laganja. Rezultati istraživanja su pokazali da ispitanici koji su uspešniji u proceni istinitosti lažnog iskaza procenjuju da su samododirivanje, pokreti šake, greške u govoru i ilustracije (učestalost pokreta šake i ruke koji imaju za cilj da poprave i/ili dopune ono što je verbalno izneto) učestaliji oblici neverbalnog ponašanja prilikom laganja, a da su pokreti trupa i pokreti nogu manje učestali u ovakvim situacijama. Moglo bi se zaključiti da bolji procenjivači laži opažaju ponašanje osoba koje daju lažan iskaz kao istovremeno „ukočeno“ i „nervozno“, što odgovara stereotipnom verovanju o neverbalnim indikatorima laganja (Vrij, 2000).

Kada je u pitanju procena istinitog iskaza, rezultati su pokazali da oni koji su u toj proceni tačniji procenjuju da su pokreti nogu, oklevanje u govoru i pokreti glave učestaliji, a samododirivanje manje učestalo neverbalno ponašanje kod osoba koje govore istinu. Ovi nalazi sugerišu da se ponašanje osoba koje govore istinu posmatra kao opuštenije i spontanije.

Dakle, osnovni zaključak na koji upućuju rezultati jeste da studenti, zapravo, veruju da se oni koji lažu ponašaju nervoznije od osoba koje govore istinu, što je pogrešno i stereotipno mišljenje. Oni koji lažu ne moraju nužno biti nervozniji, a osim toga oni mogu uspešno kontrolisati svoje ponašanje i govor i na taj način ne pokazivati znakove nervoze. Znakovi nervoze takođe mogu biti odsutni usled kognitivnog opterećenja u vezi sa lažima koje se izriču (Vrij, 2000). Ovde je pokazano da i oni koji su uspešni u procenjivanju laži svoje procene temelje na stereotipnim uverenjima, što se može interpretirati kao nastojanje da se ono što je dobro opaženo kao lažan odnosno istinit iskaz objasni ponašanjima koja 
se subjektivno uklapaju u naivne teorije o neverbalnim indikatorima laganja.

Rezultati ovog istraživanja mogu da se tretiraju kao polazna osnova za kreiranje programa edukacije u oblasti procene istinitosti iskaza. Naime, stereotipno mišljenje o ponašanju osoba koje lažu sadrži pojednostavljeno uverenje o pokazateljima laganja, a posledica je nedostatka znanja o ovoj veoma značajnoj oblasti, posebno u radu policije. Iz navedenog razloga verujemo da bi u ovom istraživanju studenti postigli bolje rezultate da su prethodno bili edukovani i edukacijom stekli barem elementarna znanja koja se tiču oblasti neverbalne komunikacije i obmane, kao i oblasti psihologije iskaza. Obrazovanje i trening policijskih službenika ili drugih službenika i stručnjaka koji vrše procenjivanje (carinici, zatvorski službenici, sudije, psiholozi itd.) trebalo bi da ima pozitivan uticaj na tačnost razlikovanja osoba koje lažu od onih koji govore istinu. Studije koje su sproveli istaknuti istraživači (Ekman, 1991; Vrij, Edward, Roberts \& Bull 2000; Vrij, Evans, Akehurst \& Mann 2004; De Paulo, Lassiter \& Stone 1982; DeTurck, 1991; Köhneken 1987), podržavaju napred navedeno mišljenje.

\section{Literatura}

De Paulo, B.M., Charlton, K., Cooper, H., Lindsay, J.L., \& Muhlenbruck, L. (1997). The accuracy-confidence correlation in the detection of deception. Personality and Social Psychology Review, 1, 346-357.

De Paulo, B.M., Lassiter, G.D. \& Stone, J.I. (1982). Attentional determinants of succes at detecting deception and truth. Personality and social psychology Bulletin, 8, 273-279.

De Turck, M.A. (1991). Training observers to detect spontaneous deception: Effects og gender. Comminication Reports, 4, 81-89.

Ekman, P. (1991). Telling lies. New York: W.W.Norton.

Ekman, P. \& O'Sullivan, M. (1991). Who can catch a liar? American Psychologist, 46, 913-920.

Global Deception Research Team (2006). A World of Lies. Journal of Cross cultural Psychology, 37, 60-74.

Kapardis, A. (2001). Psychology and Law. Cambridge: Cambridge University Press.

Köhnken, G. (1987). Training police officers to detect deceptive eyewitness statement. Does it work? Social Behaviour, 2, 1-17. 
Riggio, R.E. \& Friedman, H.S. (1983). Individual differences and cues to deception. Journal of Personality and Social Psychology, 45, 899-915.

Vrij, A. (2000). Detecting Lies and Deceit. Chichester: John Wiley \& Sons Ltd.

Vrij, A., Evans, H., Akehurst, L. \& Mann, S. (2004). Rapid judgements in assessing verbal and nonverbal cues; Their potential for deception researchers and lie detection. Applied Cognitive Psychology, 18, 283-296.

Vrij, A., Edward, K., Roberts, K. P., \& Bull, R. (2000). Detecting deceit via analysis of verbal and nonverbal behavior. Journal of Nonverbal Behavior, 24, 239 $-263$.

Vrij, A. \& Winkel, F.W. (1991). Cultural patterns in Dutch and Surinam nonverbal behavior: An analysis of simulated police/citizen encounters. Journal of Nonverbal Behavior, 15, 169-184.

\section{Prilozi}

Prilog 1. Kontingencijska tabela za varijable istinitost iskaza i tačnost procene

\begin{tabular}{|c|c|c|c|}
\hline & Lažni iskaz & Tačna procena & Netačna procena \\
\hline 1 & & 193 & 207 \\
\hline 2 & & 48.3 & 51.8 \\
\hline 3 & & 49.4 & 50.0 \\
\hline 4 & Istinit iskaz & 198 & 202 \\
\hline 5 & & 49.5 & 50.5 \\
\hline 6 & & 50.6 & 49.4 \\
\hline 7 & & 48.9 & 51.1 \\
\hline
\end{tabular}

Prilog 2. Redni broj procenitelja - tačnost procene

\begin{tabular}{lcc}
\hline & Tačna procena & Netačna procena \\
\hline 1 & 3 & 7 \\
\hline 2 & 3 & 7 \\
\hline 3 & 3 & 7 \\
\hline 4 & 2 & 8 \\
\hline 5 & 4 & 6 \\
\hline 6 & 6 & 4 \\
\hline 7 & 4 & 6 \\
\hline 8 & 6 & 4 \\
\hline
\end{tabular}




\begin{tabular}{|c|c|c|}
\hline 9 & 4 & 6 \\
\hline 10 & 4 & 6 \\
\hline 11 & 8 & 2 \\
\hline 12 & 4 & 6 \\
\hline 13 & 6 & 4 \\
\hline 14 & 6 & 4 \\
\hline 15 & 5 & 5 \\
\hline 16 & 7 & 3 \\
\hline 17 & 6 & 4 \\
\hline 18 & 6 & 4 \\
\hline 19 & 6 & 4 \\
\hline 20 & 4 & 6 \\
\hline 21 & 6 & 4 \\
\hline 22 & 6 & 4 \\
\hline 23 & 4 & 6 \\
\hline 24 & 4 & 6 \\
\hline 25 & 6 & 4 \\
\hline 26 & 4 & 6 \\
\hline 27 & 6 & 4 \\
\hline 28 & 6 & 4 \\
\hline 29 & 4 & 6 \\
\hline 30 & 6 & 4 \\
\hline 31 & 5 & 5 \\
\hline 32 & 4 & 6 \\
\hline 33 & 4 & 6 \\
\hline 34 & 5 & 5 \\
\hline 35 & 6 & 4 \\
\hline 36 & 6 & 4 \\
\hline 37 & 4 & 6 \\
\hline 38 & 4 & 6 \\
\hline 39 & 6 & 4 \\
\hline 40 & 5 & 5 \\
\hline 41 & 3 & 7 \\
\hline 42 & 4 & 6 \\
\hline 43 & 6 & 4 \\
\hline 44 & 4 & 6 \\
\hline 45 & 4 & 6 \\
\hline 46 & 4 & 6 \\
\hline 47 & 5 & 5 \\
\hline 48 & 4 & 6 \\
\hline 49 & 2 & 8 \\
\hline 50 & 4 & 6 \\
\hline 51 & 4 & 6 \\
\hline 52 & 7 & 3 \\
\hline 53 & 4 & 6 \\
\hline 54 & 5 & 5 \\
\hline
\end{tabular}




\begin{tabular}{lll}
\hline 55 & 8 & 2 \\
\hline 56 & 5 & 5 \\
\hline 57 & 4 & 6 \\
\hline 58 & 6 & 4 \\
\hline 59 & 5 & 5 \\
\hline 60 & 4 & 6 \\
\hline 61 & 6 & 4 \\
\hline 62 & 4 & 6 \\
\hline 63 & 4 & 6 \\
\hline 64 & 5 & 5 \\
\hline 65 & 4 & 6 \\
\hline 66 & 5 & 5 \\
\hline 67 & 5 & 5 \\
\hline 68 & 4 & 6 \\
\hline 69 & 4 & 6 \\
\hline 70 & 6 & 4 \\
\hline 71 & 4 & 6 \\
\hline 72 & 5 & 5 \\
\hline 73 & 5 & 5 \\
\hline 74 & 3 & 7 \\
\hline 75 & 5 & 5 \\
\hline 76 & 7 & 3 \\
\hline 77 & 6 & 4 \\
\hline 78 & 4 & 6 \\
\hline 79 & 8 & 2 \\
\hline 80 & 7 & 3 \\
\hline
\end{tabular}


Valentina Baić

\section{Assessment Of Lying: The Accuracy And The Non-Verbal Indicators}

The aims of the study were (1) to determine the accuracy of the assessment of lying, and (2) to explore the correlation between the accuracy of assessment and the estimation of frequency of certain nonverbal behaviours. The study was conducted on a sample of 90 students of Police Academy in Zemun, Serbia. The sample was divided into two subsamples. The first one comprised ten junior students ( 6 men and 4 women). Five of them were asked to present true statements, while the other five were asked to deliver false statements. All the statements were filmed and presented to the second group of students. That group was consisted of 80 senior students (58 men and 22 women, aged 21 to 25). They had two tasks - to determine whether each statement was true or false, and to estimate the frequency of presenters'non-verbal behaviours. The frequency of non-verbal behaviours was assessed using Vrij's questionnaire.

Results show that the students' estimation of lying is less accurate than the estimation based on random guessing. Also, there are substantial individual differences in recognition of lying. The subjects who detect false statements more accurately, tend to perceive self-touching, hand movements, errors in speech and illustrations as more frequent. The same subjects perceive upper body movements and leg movements as less frequent. The subjects who were more accurate in the assessment of true statements report that leg movements, hesitation during speech and head movements were more frequent, while self-touching is less frequent. The behaviour of "liars" is perceived as more tense, which is in accordance with stereotypical views on indicators of deception. The results may be used in the creation of training programs in recognition of lying.

Key words: non-verbal behavior, non-verbal indicators of deception, lie, deceit, detecting deceit. 